\title{
Molecular Association State of Bovine Serum Albumin and Its Effect on Emulsifying Activity
}

\author{
Zahurul Haque and John E. Kinsella \\ Institute of Food Science, Cornell University, \\ Ithaca, N.Y. 14853, U.S.A.
}

Received October 20,1987

\begin{abstract}
Oil-in-water (4:6) emulsions stabilized with bovine serum albumin (BSA) (0.225 mM), at pH 7 , were used to study the effects of molecular association on the viscosity of emulsions and emulsifying activity (EA). Anions $-\mathrm{TCA}^{-}$and $-\mathrm{SO}_{4}^{-}$had different effects on the intermolecular association of BSA. Aggregates (A) of BSA comprising $A_{1}, A_{2}, A_{3}, A_{4}, A_{5}, A_{6}$ and $A_{7}$ were detected in the control and the anion ( $100 \mathrm{~mm}$ ) containing emuisions. The extent of association of BSA was in the order; control $>-\mathrm{SO}_{4}^{-}>-\mathrm{TCA}^{-}$. The EA also showed the same order whereas the viscosity of emulsions showed the reverse order. High energy input per unit volume $\left(>68410^{6} \mathrm{~J} \cdot \mathrm{m}^{-3}\right)$ caused molecular dissociation and a concomitant decrease in EA. Apparently, a certain degree of association is required for $\mathrm{EA}$ of BSA
\end{abstract}

The role of an emulsifier at the oil-water interface is multifaceted. ${ }^{1)}$ It has to be amphipathic, flexible $e^{2,3)}$ and capable of controlled intermolecular association in forming a stable interfacial film that has flexibility, and has to provide long range steric hindrance without significantly decreasing the surface tension. ${ }^{2,4)}$

Some proteins are capable of meeting many of the requirements of an emulsifier." The conformation of proteins can alter in the oilwater interface during the process of emulsification because of shear forces and the apolarity of the oil-phase, which perturbs the forces responsible for protein folding. Previous experiments indicated that the EA of BSA decreases with a high energy input per unit volume $(E)\left(>680 \quad 10^{6} \mathrm{~J} \cdot \mathrm{m}^{-3}\right)$ during continuous homogenization. ${ }^{5)}$ This change in the EA may be a reflection of changes in the intermolecular association state of BSA. Thus, increased intermolecular association could strengthen the interfacial film whereas dissociation might weaken the film.

The relationship between the association of BSA and EA has not yet been elucidated. In this study, BSA stabilized oil-in-water type emulsions were used to determine whether or not protein association affects the EA of BSA.

\section{MATERIALS AND METHODS}

Materials. Bovine serum albumin (BSA) (Cohn fraction 5, product No. A-9647) was from Sigma, St. Louis, MO. A standard protein molecular weight (higher) reference kit was purchased from Pharmacia, Uppsala, Sweden. Recrystallized urea (low cyanate) was obtained from Pierce Chemical Co., Rockford, IL. Commercial grade edible peanut oil lacking emulsifiers $\left(921 \mathrm{~kg} / \mathrm{m}^{3}\right)$ was purchased from Planters. All other reagents were of analytical grade.

\section{Methods.}

Emulsion preparations. A recirculating valve homogenizer was used for making all the emulsions under controlled conditions, as described previously. ${ }^{6)}$ The mean power density $(\ddot{E})$ was kept constant at $6.210^{9} \mathrm{~W} \cdot \mathrm{m}^{-3}$, the $\mathrm{pH}$ was 7 , the oil: water ratio $(\mathrm{o}: \mathrm{w})$ was $4: 6$ and the protein concentration was $0.225 \mathrm{~mm}$. Because $\mathrm{E}$ has a cumulative effect on the EA, ${ }^{6}$ emulsions prepared with various levels of $\mathbf{E}$ were obtained by recirculating the emulsion through a heat exchanger back to the feed hopper at a constant rate. $A$ profile of the maximum pressure drop at the homogenizer valve-head $\left(\Delta P_{\max }\right)$ was obtained by the computerized method, as described previously. ${ }^{6)}$

Determination of the state of association. To determine whether or not BSA formed aggregates during emulsification, aliquots (21) of a freshly prepared emulsion were injected directly into a high performance liquid chromatographic system (Water-M45). A $30 \mathrm{~cm} \times 7.5 \mathrm{~mm}$ i.d. hy- 
drophilic glass bead gel filtration type column (TSK Gel G3000 W) (Toyo Soda, Tokyo, Japan), equipped with a Millipore (HA) $0.45 \mathrm{~m}$ filter and a Toyo Soda TSK-SWP10 (75 mm $\times 7.5 \mathrm{~mm}$ i.d.) guard column, was used for all the experiments. The standard HPLC buffer used was $20 \mathrm{~mm}$ imidazole- $\mathrm{HCl}$, pH $7\left(25^{\circ} \mathrm{C}\right)$, and the flow rate was $1 \mathrm{ml} / \mathrm{min}$. Because of the samll injection volume (21) 10 samples could be analyzed before the HPLC system has to be cleaned, first with $500 \mathrm{ml}$ of $25 \%$ ethylene glycol containing $1 \mathrm{M} \mathrm{NaCl}$ and $2 \mathrm{M}$ urea, followed by with $200 \mathrm{ml}$ of $5 \mathrm{M}$ recrystallized urea (low cyanate) and finally with $500 \mathrm{ml}$ of the standard HPLC buffer. The Millipore filter was changed frequently and the guard column was changed when the HPLC pressure increased above normal ( $>50$ PSI).

The viscosity of the BSA stabilized emulsions was determined with a Brookfield Synchro-lectric Viscometer (Brookfield model LVT) with an UL adapter at the rate of $12 \mathrm{rpm}$ at $25^{\circ} \mathrm{C}$. An emulsion $(20 \mathrm{ml})$ was poured into the temperature equilibrated UL adapter and then measurements were made immediately. The results presented are the means for three experiments.

\section{RESULTS AND DISCUSSION}

Based on comparison of the HPLC retention times of BSA aggregates in the emulsions with the retention times of standard molecular weight references (Pharmacia, Uppsala, Sweden), the tetramer $\left(\mathrm{A}_{4}\right)$ was found to be the predominant BSA aggregate in the normal (control) emulsions. The other components included the pentamer $\left(\mathrm{A}_{5}\right)$, hexamer $\left(A_{6}\right)$ and heptamer $\left(A_{7}\right)$ (Fig. 1A). Protein extraction steps with urea or a surfactant (SDS), were avoided because they would have caused dissociation of the BSA complex. Since the emulsions were injected as such, the HPLC data should reflect the association state of the protein complexes in the emulsions.

During the initial stages of homogenization $\left(<20010^{6} \mathrm{~J} \cdot \mathrm{m}^{-3}\right)$, there was an increase in the $\mathrm{A}_{5}$ complex with a concomitant decrease in the $\mathrm{A}_{4}$ complex, e.g., the ratio of $\mathrm{A}_{5}$ to $\mathrm{A}_{4}$, which was $1: 4$ at $0 E$, increased to $2.5: 4$ at an $E$ of $20010^{6} \mathrm{~J} \cdot \mathrm{m}^{-3}$ (Fig. 1A). The $\mathrm{A}_{5}$ complex disappeared as the E exceeded $100010^{6} \mathrm{~J} \cdot \mathrm{m}^{-6}$. There was an overall decrease in the $A_{5}$ and $A_{6}$ aggregates at higher $E\left(>80010^{6} \mathrm{~J} \cdot \mathrm{m}^{-3}\right)$. The largest aggregate $\left(\mathrm{A}_{7}\right)$ increased in this region.

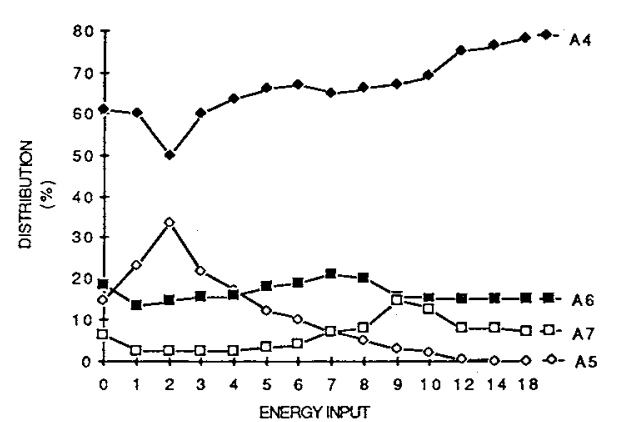

(A)

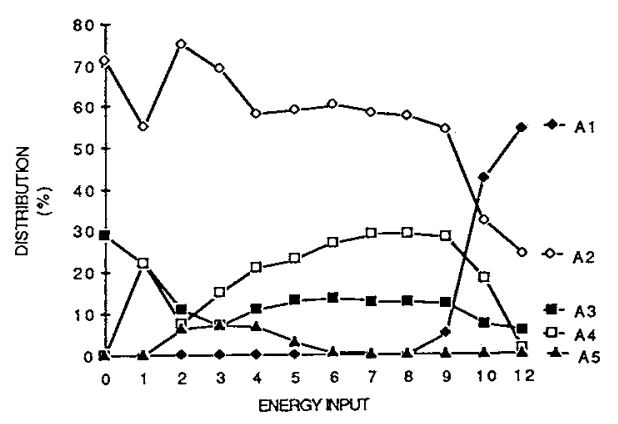

(B)

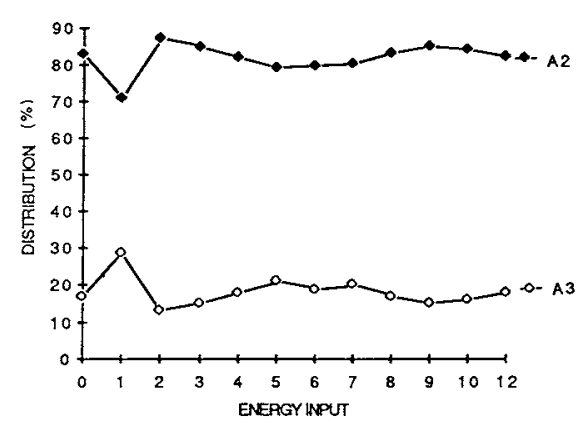

(C)

FIG. 1. Distribution of the Different Protein Aggregates in Bovine Serum Albumin (BSA) Stabilized Emulsions Following Different Levels of Energy Input per Unit Volume.

Energy input per unit volume is expressed in $10^{8} \mathrm{~J} \cdot \mathrm{m}^{-3}$ and the distribution represents the normalized percentile distribution. The protein concentration was $0.225 \mathrm{~mm}$ (in the aqueous phase), the oil/water ratio was $4: 6$ and the $\mathrm{pH}$ was 7 , in $20 \mathrm{~mm}$ imidazole- $\mathrm{HCl}$.

(A) BSA stabilized normal emulsion (control). (B) BSA emulsion containing $100 \mathrm{mM}^{-} \mathrm{TCA}^{-}$. (C) BSA emulsion containing $100 \mathrm{~mm}-\mathrm{SO}_{4}^{-}$.

Previous experiments showed that the EA of BSA decreased in this high $E$ region. ${ }^{5}$ ) These results suggest that a limited degree of aggre- 


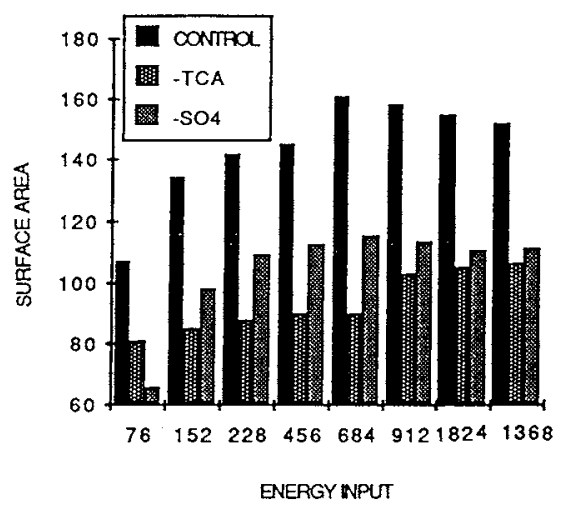

FIG. 2. Histogram Showing the Relative Emulsifying Activity of BSA (Control) and in the Presence of Anions.

Surface area is expressed in $\mathrm{m}^{2} / \mathrm{g}$ of BSA, and energy input per unit volume in $10^{6} \mathrm{~J} \cdot \mathrm{m}^{-3}$.

gation via intermolecular association may be required for $\mathrm{EA}$.

To elucidate the possible mechanisms involved in emulsion destabilization at high $E$, similar analyses were conducted on emulsions containing trichloroacetic acid $\left(-\mathrm{TCA}^{-}\right)$. At the concentration used $(100 \mathrm{~mm}),-\mathrm{TCA}^{-}$ should have a negligible effect on the water structure, i.e., on hydrophobic effects per se, but rather by binding to BSA render the molecules predominantly anionic, and hence should decrease protein-protein association. ${ }^{7,8)}$

In the presence of $-\mathrm{TCA}^{-}$, the BSA molecules were mostly dimeric $\left(\mathrm{A}_{2}\right)$ (Fig. 1B) in the oil/water mixture prior to homogenization. On homogenization, the $\mathrm{A}_{4}$ aggregate, which was the predominant species in the control (without anions) emulsions (Fig. 1A), increased slowly with $E$ but decreased rapidly at $E s>90010^{6} \mathrm{~J} \cdot \mathrm{m}^{-3}$. There was a concomitant increase in the $A_{1}$ (monomer) form, reflecting dissociation presumably via charge repulsion. The results (Fig. 2) indicate that the overall EA in $-\mathrm{TCA}^{-}$was poor.

To further confirm the importance of association for the EA of $\mathrm{BSA},-\mathrm{SO}_{4}{ }^{-}(100 \mathrm{~mm})$, an anion that has a low affinity for binding with proteins, ${ }^{8)}$ was used. The HPLC studies indicated that $A_{2}$ and $A_{3}$ (Fig. 1C) were the predominant aggregstes in $-\mathrm{SO}_{4}{ }^{-}$, i.e., there

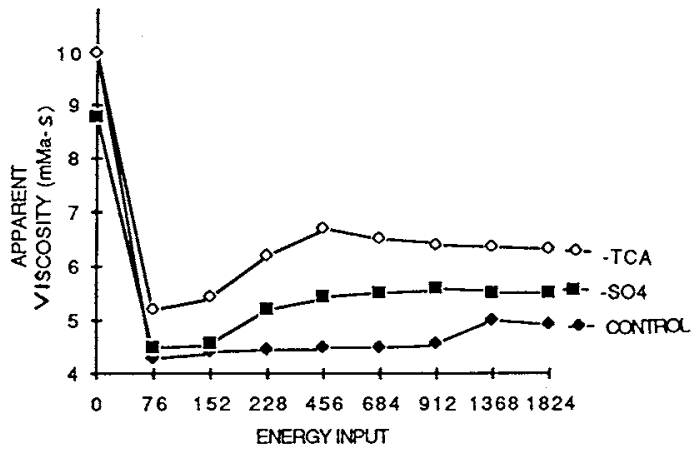

FIG. 3. Apparent Viscosity of Emulsions Prepared in the Absence and Presence of Anions.

All the conditions were as in Fig. 4.

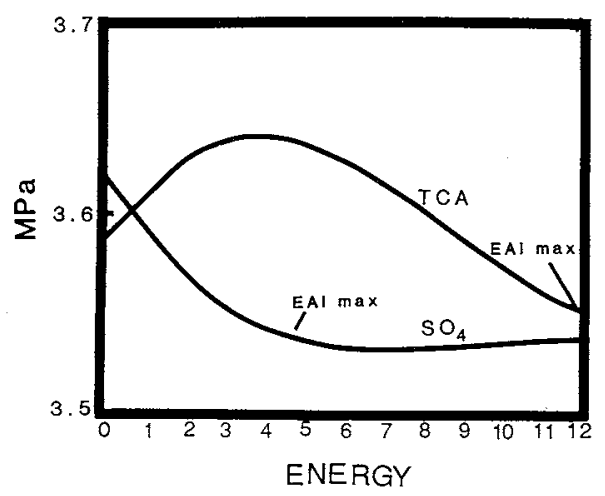

FIG. 4. Valve-head Pressure (MPa) Profiles Reflecting the Apparent Viscosity of Emulsions in the Presence of Anions.

The energy input per unit volume is expressed in $10^{8} \mathrm{~J} \cdot \mathrm{m}^{-3} . \mathrm{EAI}_{\max }$ represents the region in which the maximum emulsifying activity was reached. All other conditions were as in Fig. 2.

were fewer larger aggregates than in the control emulsions. Since the protein concentration was constant $(0.225 \mathrm{~mm})$, the total number of protein particles (aggregates) available for interactions and spreading at the interface was greater than in the control emulsions. However, the EA was less (Fig. 2). The overall EA showed the order, control $>-\mathrm{SO}_{4}{ }^{-}>-\mathrm{TCA}$, which was also the order of the degree of aggregation, suggesting a relationship between the association of BSA and EA.

The apparent viscosity of the emulsions showed the order, control $<-\mathrm{SO}_{4}{ }^{-}<-\mathrm{TCA}^{-}$, at all levels of $E$ (Fig. 3). The $\Delta P_{\max }$ profiles of 
the emulsions were comparable to the Brookfield apparent viscosities, and there was a negative relationship between viscosity and EA (Fig. 4). Such a relationship between viscosity and EA has already been observed and discussed. ${ }^{5,9)}$

These observations suggest a relationship between BSA association and emulsion formation. A decrease in the association of BSA appeared to be one factor responsible for destabilization of BSA stabilized emulsions.

Acknowledgment. This work was supported in part by a grant from the National Dairy Board.

\section{REFERENCES}

1) J. E. Kinsella, CRC Crit. Rev. Food Sci. Nutr., 7, 219
(1976).

2) Z. Haque and M. Kito, J. Agric. Food Chem., 32, 1392 (1984).

3) Z. Haque and M. Kito, J. Agric. Food Chem., 31, 1231 (1984).

4) S. Friberg, in "Food Emulsions," ed. by S. Friberg, Marcel Dekker, Inc., New York and Basel, 1986.

5) Z. Haque and J. E. Kinsella, J. Food Sci, in press, 1988 .

6) Z. Haque and J. E. Kinsella, J. Food Sci., 53, in press, 1988.

7) F. Hofmeister, Arch. Exptl. Pathol. Pharmakol, 24, 247 (1888).

8) U. Feitknecht, S. Gral and R. Signer, Helv. Chim. Acta, 46, 813 (1963).

9) Z. Haque, J. Leman and J. E. Kinsella, J. Food Sci., 53, in press, 1988.

10) C. Tanford, "The Hydrophobic Effect: Formation of Micelles and Membranes," Wiley, New York, 1980. 